\title{
The pharmacological effect of apricot seeds extracts and amygdalin in experimentally induced liver damage and hepatocellular carcinoma
}

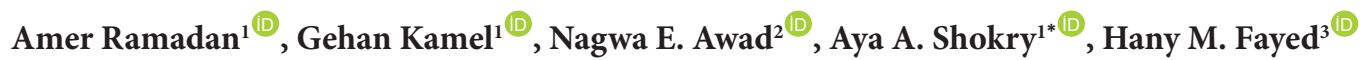 \\ ${ }^{1}$ Department of Pharmacology, Faculty of Veterinary Medicine, Cairo University, Cairo, Egypt. \\ ${ }^{2}$ Department of Pharmacognosy, Pharmaceutical and Drug Industrial Research Division, National Research Center, Giza, Egypt \\ ${ }^{3}$ Pharmacology Department, Medical Division, National Research Center, Giza, Egypt
}

\section{A R T I C L E I N F O}

Article Type:

Original Article

\section{Article History:}

Received: 12 January 2020

Accepted: 7 May 2020

\section{Keywords:}

Hepatocellular carcinoma

Hepatoprotective drug

$\mathrm{CCl} 4$

Apricot seeds

Amygdalin

\begin{abstract}
A B S T R A C T
Introduction: Apricot (Prunus armeniaca L.) has been widely used for the treatment of several disorders such as liver diseases, but the hepatoprotective and anticancer activities of its seeds were not studied before. In this study, we evaluated the pharmacological effects of apricot seeds extracts and amygdalin on prevention of liver damage and treatment of hepatocellular carcinoma.

Methods: Amygdalin contents of apricot seeds in ethanolic extracts were determined using high performance liquid chromatography (HPLC) then, the ethanolic apricot seeds extract and amygdalin were evaluated for its hepatoprotective activity against carbon tetrachlorideinduced hepatotoxicity and anticancer activity against N-nitrosodiethylamine (NDEA)induced hepatocarcinogenesis.

Results: The amount of amygdalin was $5.72 \mathrm{~g}$ and $10.22 \mathrm{~g} / 100 \mathrm{~g}$ extract for $70 \%$ and $99.9 \%$ ethanolic apricot seeds extracts, respectively. Pretreatment of the rats with $70 \%$ and $99.9 \%$ ethanolic apricot seeds extracts $(100 \mathrm{mg} / \mathrm{kg})$, amygdalin and silymarin $(50 \mathrm{mg} / \mathrm{kg})$ prevented elevation in liver function parameters such as alanine aminotransferase (ALT), aspartate aminotransferase (AST), alkaline phosphatase (ALP) caused by carbon tetrachloride injection with significant increase in albumin, total proteins, and no effect on total direct bilirubin when compared to those in hepatotoxic group. Both extracts also showed anticancer activity against hepatocellular carcinoma via diminishing the elevated serum levels of AST, ALT, ALP, total, direct bilirubin, albumin, total proteins, alpha-fetoprotein, malondialdehyde (MDA) and nitric oxide (NO) and elevating the decreased hepatic reduced glutathione (GSH) level when compared with NDEA- intoxicated group.

Conclusion: Apricot seeds possess hepatoprotective and anticancer activities that justify its traditional use, and its potential for the treatment of liver diseases including hepatocellular carcinoma.
\end{abstract}

Implication for health policy/practice/research/medical education:

This work provides information about the pharmacological activities of apricot seeds and its major component amygdalin in prevention of liver damage induced by carbon tetrachloride and treatment of hepatocellular carcinoma induced by nitrosodiethylamine in rats. Our results indicate that apricot seeds or amygdalin as pure powder can treat hepatocellular carcinoma and prevent liver damage. So, they might be used for therapy or as preventive drug.

Please cite this paper as: Ramadan A, Kamel G, Awad NE, Shokry AA, Fayed HM. The pharmacological effect of apricot seeds extracts and amygdalin in experimentally induced liver damage and hepatocellular carcinoma. J Herbmed Pharmacol. 2020;9(4):400-407. doi: 10.34172/jhp.2020.50.

\section{Introduction}

Injury of the liver is one of the main health challenges in the world (1). Several etiologies such as viral infection, exposure to toxins, drug overdose and chronic cholestatic diseases have been associated with the development of liver disease (2). Chronic liver diseases are characterized by bad sequels started with steatosis to chronic hepatitis, fibrosis, cirrhosis, and finally hepatocellular carcinoma (HCC) (3). Hepatocarcinogenesis initiated via sustained inflammation with release of free radicals and lipid 
peroxidation which in turn interact directly with DNA, damaging specific genes that control cell growth and differentiation (4). The repetitive chronic injury and cellular regenerative events could result in genomic aberrations and mutations of tumor-suppressor genes leading to the development of HCC (5).

Lacking of safe drugs for the treatment of liver diseases have shown a significant concern in finding natural products used in medicinal materials or foods (6). Medicinal plant extracts had gained increasing interest as non-drug remedy for several diseases. This may be due to their active constituents that modulate oxidative stress and cell damage (7). Phytochemicals with anti-inflammatory, antibacterial, anti-oxidant, and anti-mutagenic properties are extremely attractive potential agents for preventing diseases in humans (8).

Apricot (Prunus armeniaca L.), the Prunus species of Rosaceae family, has become a product of great interest, being a rich source of health beneficial nutrients (carbohydrates, vitamins $\mathrm{A}, \mathrm{C}$ and $\mathrm{E}$, minerals, fibers) and phytochemicals (polyphenolics, carotenoids and glycosides) (9). It is well-known that apricot is rich in phenolic substances such as catechin, epicatechin, p-coumaric acid, caffeic acid, ferulic acid and their esters (10). Chlorogenic acid is the dominant ester in apricot (11). A variety of pharmacological effects of apricot and its kernel are reported including, antiparasitic, sedative, anti-inflammatory, antimicrobial, antimutagenic, antispasmolytic, antitussive, anticancer, antiaging, antiatherosclerating, antianginal, cardioprotective, hepatoprotective, renoprotective and antioxidant (especially $\beta$-carotene) (12).

Armeniacae semen, the seed of the apricot, be used traditionally to relieve fever, stop cough. It is used for the treatment of asthma, bronchitis, emphysema, constipation, nausea, leprosy, and leukoderma (13). Apricot kernel paste can heal vaginal infections. The kernel oil has been used in cosmetics and as a pharmaceutical agent (laxative and expectorant) (14).

Apricot seeds contain a chemical substance is known as Amygdalin which is naturally cyanogenic glycoside known as vitamin B17 (15). It can be used for treating skin diseases such as furuncle, acne vulgaris and dandruff, preventing and treating migraine, hypertension, chronic inflammation, constipation and other diseases (16).

Amygdalin can specifically attack cancer cells without affecting other healthy cells, it affects cell cycle inducing apoptosis with cytotoxic effect through interaction with $\beta$-glucosidase enzyme which present only in cancer cells inducing hydrolysis of glycosidic bond between sugar and aryl group with inhibition of cytochrome oxidase enzyme and releasing large amount of hydrocyanic acid which induces cell death, but the normal cells contain rhodanese enzyme which convert the hydrocyanic acid to non-toxic substance (17). The present study was aimed to evaluate the hepatoprotective and anticancer potential of ethanolic apricot seeds extracts and amygdalin against experimentally-induced liver fibrosis and hepatocarcinogenesis.

\section{Materials and Methods}

Seeds

Apricot seeds were collected from Edfina factory from Alexandria, washed, dried, and the seeds were splitted from the shell.

\section{Extract preparation}

Ethanolic extract 99.9\%: The seeds were soaked in 99.9\% ethanol solution then grinded and boiled for $100 \mathrm{~min}$., at $55^{\circ} \mathrm{C}$. Extract was filtered and evaporated.

Ethanolic extract 70\%: The seeds were soaked in $70 \%$ ethanol solution with $6 \%$ citric acid then grinded and boiled for 100 minutes, at $55^{\circ} \mathrm{C}$. Extract was filtered and evaporated.

Quantitative evaluation of amygdalin in both extracts using HPLC

The HPLC system used was Smart Line, Knauer, Germany, equipped with a kinetex XB-C 18 column $100 \mathrm{~mm} \times 4.6$ $\mathrm{mm}$ (Phenomenex ${ }^{\circledR}, \mathrm{USA}$ ), operated at $30^{\circ} \mathrm{C}$ with mobile phase methanol: water 15:85 (V/V) and flow rate $0.7 \mathrm{~mL} /$ min. and injected volume $20 \mu \mathrm{L}$ The UV detector set at $215 \mathrm{~nm}$ and data integration by ClarityChrom ${ }^{\circledR}$ software.

\section{Experimental animals}

Mature male albino Wistar rats were used, weighing from 200 to 250 g obtained from laboratory animal colony, Helwan, Egypt and housed in laboratory animal house at pharmacology department, faculty of veterinary medicine, Cairo University and received standard pellets and water ad-libitum, subjected to 12 hours light and 12 hours dark. All procedures described were reviewed and approved by the University Animal Ethics Committee.

\section{Chemicals}

All chemicals were purchased from Sigma USA, Aldrich. Solvents were purchased from El Nasr Pharmaceutical chemicals Co. Egypt.

Hepatoprotective effect

This experiment was carried out according to (18). The animals were divided into six groups $(n=7)$, as follows: Group I served as normal control, received paraffin oil. Group II kept as hepatotoxic group. Group III received silymarin (50 mg/kg, P.O) for 6 weeks as a standard group. Group IV received amygdalin (50 mg/kg, P.O) for 6 weeks. Animals of group V and VI were treated with $70 \%$ and $99.9 \%$ ethanolic extracts $(100 \mathrm{mg} / \mathrm{kg}, \mathrm{P} . \mathrm{O})$ for 6 weeks. After 6 weeks, hepatotoxicity was induced in all animals except group I by intraperitoneal injection with 
fresh mixture of equal volume of carbon tetrachloride and paraffin oil (1:1) (1 mL/kg). After 24 hours, blood samples were collected from median canthus of eye.

\section{Anticancer effect}

Sixty male albino Wistar rats weighing 200-250 g were divided into 6 groups $(\mathrm{n}=10)$. Group I (normal control), received vehicles of drugs only (received $1 \mathrm{~mL}$ saline/ $\mathrm{kg}$, IP, single dose then received liquid paraffin in a dose of $3 \mathrm{ml} / \mathrm{kg}$, SC weekly for 8 weeks). The other 5 groups were given a single IP injection of $\mathrm{N}$-nitrosodiethylamine (NDEA) in a dose of $100 \mathrm{mg} / \mathrm{kg}$ (19) followed by a weekly SC injection of carbon tetrachloride (CCl4) $(3 \mathrm{~mL} / \mathrm{kg})$ for 8 weeks (20). Group II kept as control positive (hepatotoxic group). Group III (standard group) received silymarin orally at a dose of $50 \mathrm{mg} / \mathrm{kg} / \mathrm{d}$ for 8 weeks (21). Groups IV and $\mathrm{V}$ were orally administered apricot seeds extract $70 \%$ and $99.9 \%$ at a dose of $200 \mathrm{mg} / \mathrm{kg} / \mathrm{d}$ for 8 weeks. Group VI received amygdalin in a dose of $50 \mathrm{mg} / \mathrm{kg}$ for 8 weeks. At the end of the experimental period (16 weeks), blood samples were collected from median canthus of the eye. Rats were sacrificed and their livers were immediately removed, kept at $-80^{\circ} \mathrm{C}$ for further investigation.

\section{Statistical analysis}

Data were presented as means \pm SE and analyzed using commercial software statistical package for social science (SPSS $^{\odot}$ version 16) compared by one-way ANOVA and individual differences were determined by Duncan test.
The significance level at $P$ value $\leq 0.05$ was considered significant.

\section{Results}

Quantitative evaluation of amygdalin in both extracts using HPLC

The amount of amygdalin in both $70 \%$ and $99.9 \%$ ethanolic apricot seeds extracts determined by using HPLC was 5.72 and $10.22 \mathrm{~g} / 100 \mathrm{~g}$ extract. The chromatograms of HPLC are listed in Figure 1.

Hepatoprotective effect

The hepatoprotective effects of ethanolic apricot seeds extracts and amygdalin were evaluated and recorded in Figures 2-4. Oral administration of $70 \%$ and $99.9 \%$ ethanolic apricot seeds extracts $(100 \mathrm{mg} / \mathrm{kg})$, amygdalin $(50 \mathrm{mg} / \mathrm{kg})$ and silymarin $(50 \mathrm{mg} / \mathrm{kg}$ ) daily for 6 weeks prior to induction of hepatotoxicity showed significant hepatoprotective effects by significant decrease in liver enzymes (alanine aminotransferase [ALT], aspartate aminotransferase [AST], alkaline phosphatase [ALP]) and significant increase in some serum constituents such as albumin, total proteins without any effect on total, direct bilirubin when compared with CCL4 control intoxicated group.

\section{Anticancer effect}

The effects of ethanolic apricot seeds extracts and amygdalin on ALT, AST, ALP, albumin, total proteins,
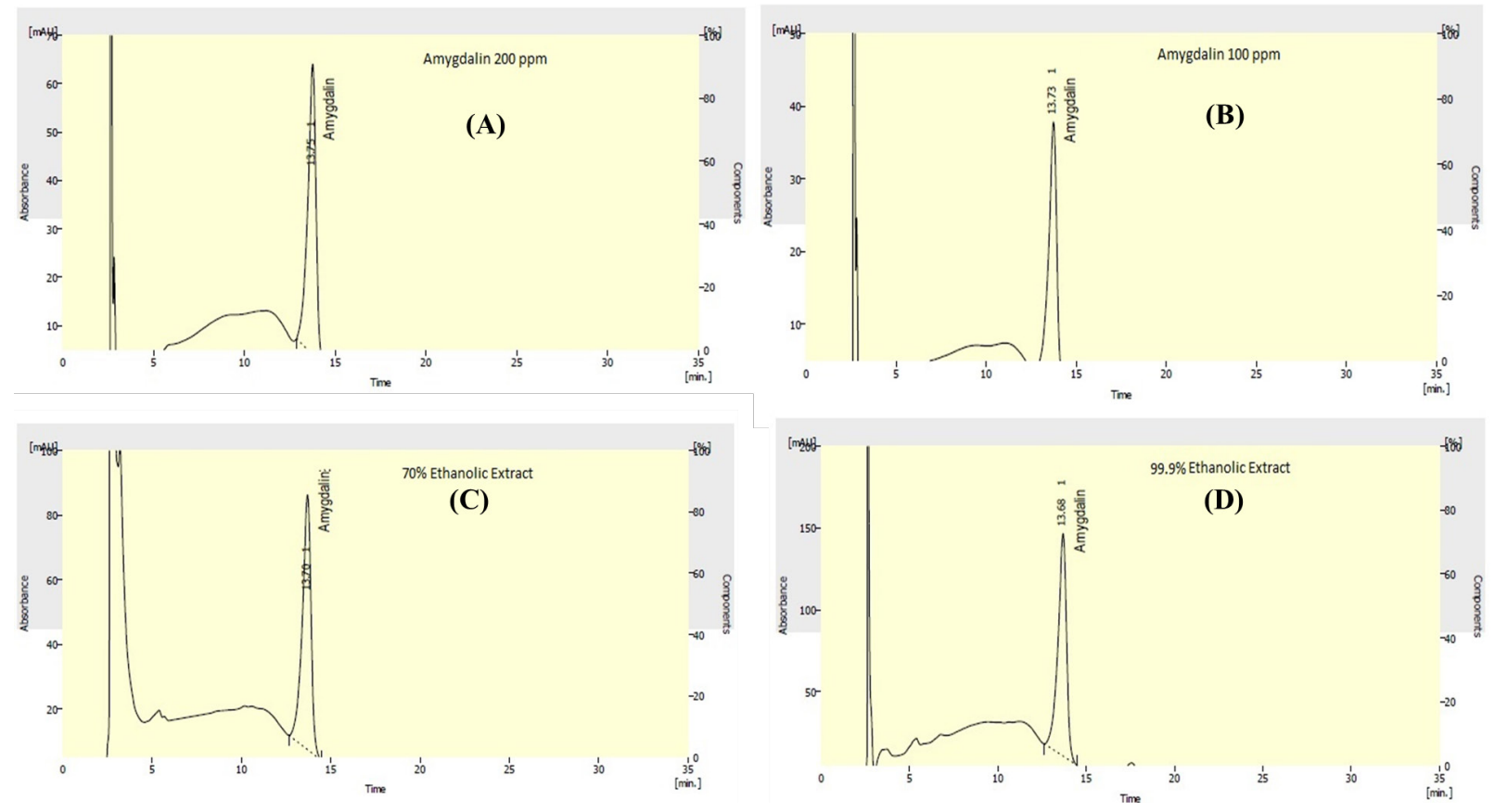

Figure 1. Chromatograms of high performance liquid chromatography using amygdalin 100 ppm (A), amygdalin 200 ppm (B), $70 \%$ ethanolic apricot seeds extract (C) and 99.9\% ethanolic apricot seeds extract (D). Chromatographic conditions were: a kinetex XB-C 18 column $100 \mathrm{~mm} \times 4.6 \mathrm{~mm}$ (Phenomenex ${ }^{\circledR}$, USA), operated at $30^{\circ} \mathrm{C}$ with mobile phase methanol: water 15:85 (V/V), flow rate $0.7 \mathrm{~mL} / \mathrm{min}$ and injected volume $20 \mu \mathrm{L}$. The UV detector was set at 215 $\mathrm{nm}$ and data integration was done by ClarityChrom ${ }^{\circledR}$ software. 


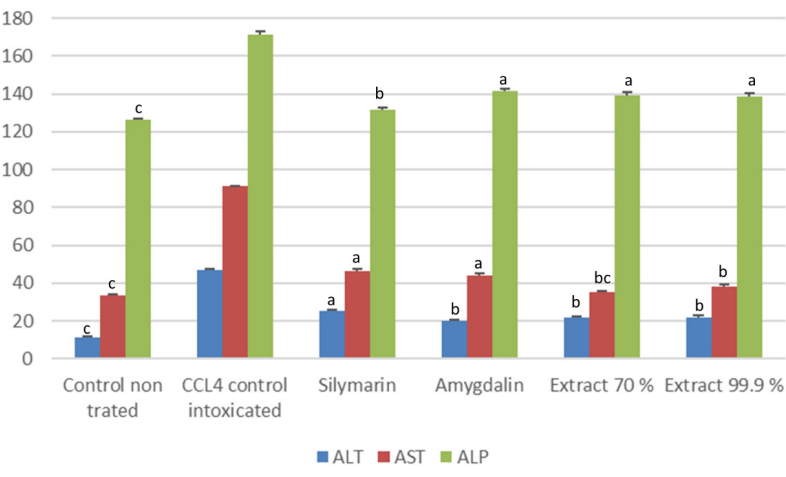

Figure 2. The effect of $70 \%$ and $99.9 \%$ ethanolic apricot seeds extracts, amygdalin and silymarin (standard) on liver enzymes, alanine aminotransferase (ALT), aspartate aminotransferase (AST), alkaline phosphatase (ALP). The data are presented as the mean \pm SE $(n=7)$. Values with different superscript letters $(a, b, c)$ are significantly different at $P<0.05$ when compared with CCL4 control intoxicated group.

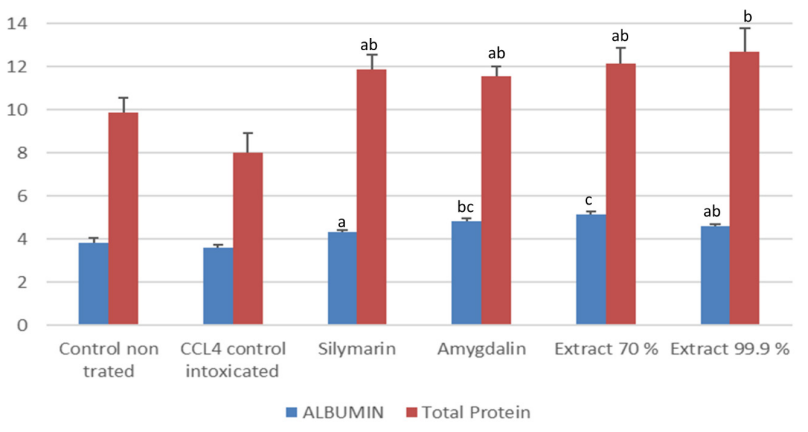

Figure 3. The effect of $70 \%$ and $99.9 \%$ ethanolic apricot seeds extracts, amygdalin and silymarin (standard) on albumin, total proteins. The data are presented as the mean \pm SE $(n=7)$. Values with different superscript letters $(\mathrm{a}, \mathrm{b}, \mathrm{c})$ are significantly different at $P<0.05$ when compared with CCL4 control intoxicated group.

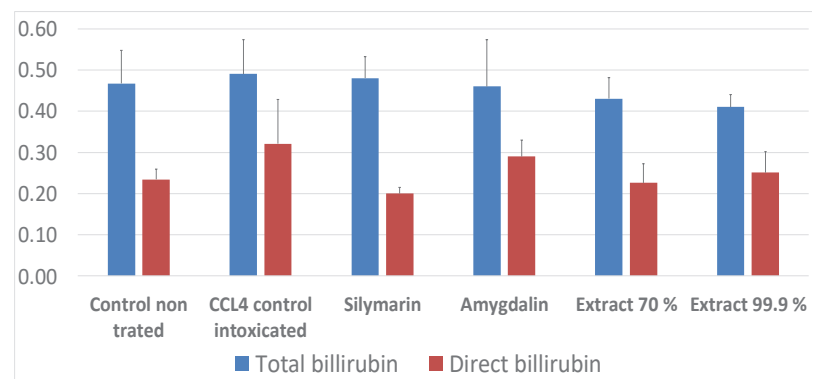

Figure 4. The effect of $70 \%$ and $99.9 \%$ ethanolic apricot seeds extracts, amygdalin and silymarin (standard) on total and direct bilirubin. The data are presented as the mean $\pm S E(n=7)$. Values showed no significant difference when compared with CCL4 control intoxicated group.

total and direct bilirubin were evaluated and recorded in Table 1 and their effects on alpha-fetoprotein (AFP), reduced glutathione (GSH), nitric oxide (NO) and malondialdehyde (MDA) were recorded in figures 5-6. The administration of single dose of $\mathrm{N}$-nitrosodiethylmine
(NDEA) (100 mg/kg) followed by weekly SC. injection of CCL4 $(3 \mathrm{~mL} / \mathrm{kg})$ for 8 weeks induced a significant increase in serum AST, ALT, ALP, AFP when compared with the normal control group. Treatment of rats with $70 \%$ and $99.9 \%$ ethanolic apricot seeds extracts $(200 \mathrm{mg} /$ $\mathrm{kg})$, amygdalin $(50 \mathrm{mg} / \mathrm{kg})$ and silymarin $(50 \mathrm{mg} / \mathrm{kg})$ for 8 weeks revealed diminishing effect in the elevated serum levels of AST, ALT, ALP, AFP when compared with NDEA- intoxicated group. Both extracts showed significant decrease on direct and total bilirubin, albumin and total proteins as well as on the hepatic oxidative stress markers including MDA, NO and significant increase in reduced GSH level in liver homogenate.

\section{Discussion}

Natural products, and their derivatives represent more than $50 \%$ of all the drugs in the treatment of various diseases (22). In this study, the potential anticancer and hepatoprotective effects of ethanolic extracts of apricot seeds, amygdalin and silymarin in $\mathrm{N}$-nitrosodiethylamine induced hepatic carcinoma and CCL4 induced hepatotoxicity were evaluated. Both extracts were obtained by using ethanol (70\% and 99.9\%). HPLC determination of amygdalin from fruit kernels require specific mobile phase with the proper dilution ratio. Methanol: water (15:85) is a good mobile phase for amygdalin separation by HPLC (23). The preliminary quantitative evaluation of amygdalin in ethanolic apricot seeds extracts by HPLC revealed that the amount of amygdalin was 5.72 and 10.22 $\mathrm{g} / 100 \mathrm{~g}$ dry extract in $70 \%$ and $99.9 \%$ ethanolic extract, respectively.

These obtained results correlate with the finding obtained by (24) who used the same optimum conditions for separation of amygdalin from apricot seeds and evaluated by HPLC.

Oral administration of both extracts $(100 \mathrm{mg} / \mathrm{kg})$ and amygdalin in $(50 \mathrm{mg} / \mathrm{kg})$ prior to intraperitoneal injection of CCL4 showed significant hepatoprotective effect of liver by significant decrease in liver enzymes (ALT, AST and ALP) and significant increase in albumin and total proteins during the period of treatment with no significant effect on total and direct bilirubin.

The hepatoprotective effect of dried apricot seeds was evaluated by measuring the level of serum liver damage marker enzymes (AST, ALT, GGT and LDH) which increased due to hepatic damage induced by alcohol and decreased in groups of animals supplemented with diet containing dried apricot seeds (25).

Feeding of ground apricot kernel ( $1.5 \mathrm{mg} / \mathrm{kg})$ for 4 weeks has improved liver fibrosis caused by dimethylnitrosamine which might be used as a therapeutic or preventive measure against hepatic fibrosis (26). The apricot kernel administration has improved biochemical values due to increase levels of oleic acid, and other polyphenols in apricot kernels. In a study the oil content of kernels varied 
Table 1. Anticancer effect of $70 \%$ and $99.9 \%$ ethanolic apricot seeds extracts, amygdalin and silymarin (standard) on ALT, AST, ALP, albumin, total proteins, total and direct bilirubin in NDEA-intoxicated rats $(n=10)$

\begin{tabular}{|c|c|c|c|c|c|c|c|c|}
\hline Groups & $\begin{array}{c}\text { Dose } \\
\mathrm{mg} / \mathrm{kg}\end{array}$ & $\begin{array}{l}\text { ALT } \\
U / L\end{array}$ & $\begin{array}{l}\text { AST } \\
U / L\end{array}$ & $\begin{array}{l}\text { ALP } \\
I U / L\end{array}$ & $\begin{array}{l}\text { Albumin } \\
\text { g/dL }\end{array}$ & $\begin{array}{c}\text { Total protein } \\
\text { g/dL }\end{array}$ & $\begin{array}{c}\text { Total bilirubin } \\
\mathrm{mg} / \mathrm{dL}\end{array}$ & $\begin{array}{c}\text { Direct bilirubin } \\
\mathrm{mg} / \mathrm{dL}\end{array}$ \\
\hline $\begin{array}{l}\text { Control } \\
\text { (non-treated) }\end{array}$ & 0 & $22.86 \pm 0.67^{c}$ & $44.14 \pm 1.5^{c}$ & $127.4 \pm 0.76^{c}$ & $4.19 \pm 0.39^{b}$ & $9.84 \pm 0.69^{a b}$ & $0.47 \pm 0.08^{a}$ & $0.19 \pm 0.04^{a}$ \\
\hline $\begin{array}{l}\text { NDEA control } \\
\text { intoxicated }\end{array}$ & $\begin{array}{l}100 \text { followed } \\
\text { by } 3 \mathrm{~mL} \mathrm{CCL4}\end{array}$ & $67.43 \pm 1.45$ & $182 \pm 3.02$ & $191.53 \pm 3.95$ & $2.32 \pm 0.32$ & $6.46 \pm 0.54$ & $3.8 \pm 0.54$ & $1.78 \pm 0.11$ \\
\hline $\begin{array}{l}\text { Silymarin } \\
\text { (standard) }\end{array}$ & 50 & $28 \pm 1.11^{b}$ & $73.71 \pm 1.7^{b}$ & $133.7 \pm 2.15^{c}$ & $3.29 \pm 0.23^{\mathrm{a}}$ & $9.90 \pm 0.84^{\mathrm{ab}}$ & $0.61 \pm 0.03^{\mathrm{a}}$ & $0.20 \pm 0.02^{a}$ \\
\hline Amygdalin & 50 & $32.7 \pm 0.35^{a}$ & $87.86 \pm 2.01^{a}$ & $140.12 \pm 2.34^{b}$ & $3.40 \pm 0.19^{a b}$ & $8.62 \pm 0.88^{a}$ & $0.71 \pm 0.07^{a}$ & $0.29 \pm 0.04^{a}$ \\
\hline $\begin{array}{l}70 \% \text { ethanolic } \\
\text { extract }\end{array}$ & 200 & $28.14 \pm 0.51^{b}$ & $90.8 \pm 1.06^{a}$ & $141.01 \pm 2.3^{\mathrm{ab}}$ & $3.37 \pm 0.17^{\mathrm{ab}}$ & $11.10 \pm 0.35^{b}$ & $0.60 \pm 0.04^{a}$ & $0.23 \pm 0.05^{a}$ \\
\hline $\begin{array}{l}99.9 \% \text { ethanolic } \\
\text { extract }\end{array}$ & 200 & $27.29 \pm 0.87^{b}$ & $91.29 \pm 1.3^{\mathrm{a}}$ & $147.73 \pm 0.7^{a}$ & $3.40 \pm 0.23^{\mathrm{ab}}$ & $10.56 \pm 0.84^{\mathrm{ab}}$ & $0.58 \pm 0.03^{a}$ & $0.25 \pm 0.05^{\mathrm{a}}$ \\
\hline
\end{tabular}

Abbreviations: ALT, alanine aminotransferase, AST, aspartate aminotransferase, ALP, alkaline phosphatase; NDEA, Nitrosodiethylamine.

Values represent the mean \pm SE of 10 animals for each group. Values in the column with different superscript letters (a,b,c) are significantly different at $P<0.05$ when compared with NDEA intoxicated control.

from $27.7 \%$ to $66.7 \%$, the majority of fatty acids were oleic (58.3\%-73.4\%) and linoleic acids (18.8\%-31.7\%) (27). Hence, it was suggested that their dietary intake would be beneficial in protecting against hepatotoxicity (28). The presence of flavonoids, carotenoids, $\beta$-carotene, phenolic compounds and fatty acids such as oleic acid and linoleic acid which might have scavenging effects on free radicals may potentiate their hepatoprotective effects.

HCC was induced by a single IP injection of NDEA followed by weekly SCinjections of CCl4. NDEA undergoes metabolic activation via cytochrome P450 (CYP2E1) and produces the unstable promutagenic products, $\mathrm{O}^{6}$ ethyl deoxy guanosine and $\mathrm{O}^{4}, \mathrm{O}^{6}$-ethyl deoxy thymidine in the liver, which are responsible for its carcinogenic effects by interaction with DNA causing mutation (29). Additionally, $\mathrm{CCl} 4$ is biotransformed by cytochrome P450 to produce its active metabolite trichloromethyl free radical CCL3 which reacted with oxygen to form a trichloromethylperoxy radical inducing peroxidative degradation of lipids of endoplasmic reticulum initiating lipid peroxidation (30).

In our study, NDEA and CCL4 administration led to a marked increase in the levels of serum AST, ALT and ALP compared to the ones in normal rats due to the injured structural integrity of the liver as these enzymes are released from the cytoplasm of hepatocytes into the blood circulation after rupture of the plasma membrane, and cellular damage after excessive production of reactive oxygen species (31). Our results are in agreement with the results presented in (32) as they have reported similar elevation in the activities of serum AST, ALT and ALP during diethylnitrosamine administration.

Moreover, HCC group had a significant increase in serum direct and total bilirubin when compared to the normal group. These results are in agreement with the results of previous studies which revealed a highly significant increase in serum total and direct bilirubin in NDEA-intoxicated rats. Additionally, these results have been attributed to increase in a mass inhibition of the conjugation reaction, and release of unconjugated bilirubin from damaged hepatocytes (33). On the other hand, concerning the levels of serum albumin and total proteins, the current study showed a highly significant decrease in their level after administration of NDEA compound. NDEA has significantly decreased albumin level, which indicates liver dysfunction (34).

In the present study, the treatment with apricot seeds extracts and amygdalin significantly reduced serum AST, ALT, ALP, total, and direct bilirubin levels and significantly increased the reduced levels of serum albumin and total proteins when compared with NDEAintoxicated control group. This tends to treat liver damage by maintaining integrity of plasma membrane thereby suppressing the leakage of enzyme through membranes, exhibiting hepatopreventive activity. This might be a reason for restoration in activities of marker enzymes after administration of the extract.

Alpha-fetoprotein has been widely used as tumor marker for diagnosis and monitoring of HCC. An elevated level of AFP in the serum has been observed in the animals exposed to hepatocarcinogens (35). In our study, there was a marked increase in serum AFP level in HCC group when compared to the normal ones. The obtained results are in agreement with those obtained by (36) who attributed the reinitation of AFP synthesis by neoplastic hepatocytes to increase in transcription of AFP gene. The present study showed that daily administration of ethanolic apricot seeds extracts, amygdalin and silymarin significantly reduced the increased levels of serum AFP level when compared to NDEA-intoxicated rats, suggesting that apricot seeds extracts might delay the NDEA-induced HCC in rats.

In the present study, the level of malondialdehyde was 
significantly elevated by NDEA indicating increased lipid peroxidation and oxidative stress in liver. Lipid peroxidation induced by NDEA plays an important role in carcinogenesis and may lead to the formation of several toxic products, such as MDA that can attack cellular targets including DNA, thereby inducing mutagenicity and carcinogenicity (37). Also, the increases in lipid peroxidation level has been attributed to the oxidative stress leading to per-oxidative membrane damage, loss of membrane integrity and subsequent release of the cytosolic contents (38). In our study, the treated groups displayed a significant reduction in the level of MDA when compared with HCC rats. Also, liver NO level was significantly elevated in NDEA- intoxicated rats as compared to the normal group. This result matched with the results of others who reported that elevated levels of lipid peroxidation stimulated host cells, mainly monocytes and macrophages to produce and release NO by induction of inducible nitric oxide synthase (iNOS) protein, resulting in cytotoxicity and DNA damage (39). The treated groups in our study displayed a significant reduction in the level of NO when compared with NDEAintoxicated rats.

Reduced GSH is one of the major antioxidants involved in defense mechanism against lipid peroxidation in biological system and converts active oxygen molecules into non-toxic compounds (40). A reduction in GSH is associated with the accumulation of high-living free radical, leading to injury of cell function (41). Our results revealed a significant depletion in reduced GSH level after NDEA administration. These results are in agreement with previous a study who attributed the depletion in GSH level to its utilization in inactivating the free radicals generated during NDEA metabolism (42).

Apricot seeds extracts, being a rich source of antioxidant, have been able to combat the oxidative stress mediated by NDEA/CCL4, and to restore the hepatocytes damage. The anticancer effects of amygdalin may be due to that it is broken down by beta-glucosidase, which is abundant in cancer cells, and consequently cyanide is released onto the cancerous lesions inducing toxicity on the cancer cells (43). Another suggestion is that amygdalin enhances the functions of pancreatic enzymes which may prevent transformation of cancer primordial germ cells (43). It is known that amygdalin when interact with cancer cells release cyanide causing death for these cells. Amygdalin would be broken down by an enzyme in cancer cells (beta-glucosidase), and toxic cyanide to release from broken amygdalin would kill the cancer. It is known that another enzyme, rhodanese, which has the ability to detoxify cyanide, is present in normal tissues but deficient in cancer cells. These two factors combine to affect a selective poisoning of cancer cells by the cyanide, while normal cells remain undamaged (17). From these results, we can suggest that both apricot seed extracts and the pure amygdalin have powerful effects for the treatment of liver cancer when compared with control positive groups.

\section{Conclusion}

According to the data obtained from this study, the oral administration of apricot seeds or amygdalin which is the major component in seeds can prevent lipid peroxidation and protect liver from fibrosis and cirrhosis. So, they can be used for the treatment and prevention of liver dysfunction. There are many questions around apricot seeds, which need to be solved in other researches to increase knowledge about them.

\section{Authors' contributions}

AA, GK and AAS designed the protocol. NEA and AAS collected the seeds for preparation of extracts. AAS carried out the laboratory work. HMF and AAS wrote the manuscript. All authors read and revised the manuscript and confirmed its publication.

\section{Conflict of interests}

None.

\section{Ethical considerations}

All animal procedures included in this protocol were approved by Institutional Animal Care and Use Committee (IACUC) (Ethical code: CUIIF4218).

\section{Funding/Support}

There is no financial support for this work.

\section{References}

1. Kochar-kaur K, Allahbadia G, Singh M. Rosmarinic acida new hope for liver diseases like cirrhosis, hepatocellular carcinoma-needs translation to humans. EC Endocrinol Metab Res. 2019;4(6):289-301.

2. Ramadan A, Afifi N, Yassin NZ, Abdel-Rahman RF, Abd El-Rahman SS, Fayed HM. Mesalazine, an osteopontin inhibitor: The potential prophylactic and remedial roles in induced liver fibrosis in rats. Chem Biol Interact. 2018;289:109-118. doi: 10.1016/j.cbi.2018.05.002.

3. Siddiqui MA, Siddiqui HH, Mishra A, Usmani A. Epidemiology of hepatocellular carcinoma. Int J Pharm Sci Res. 2018;9(12):5050-9.

4. Afifi N, A R, Yassin NZ, Fayed HM, Abdel-Rahman RF. Molecular mechanisms underlying hepatoprotective effect of artichoke extract: modulates TNF-induced activation of nuclear transcription factor (NF-KAPPA $ß$ ) and oxidative burst inhibition. World J Pharm Pharm Sci. 2015;4(1):15461562.

5. George J, Tsuchishima M, Tsutsumi M. Molecular mechanisms in the pathogenesis of $\mathrm{N}$-nitrosodimethylamine induced hepatic fibrosis. Cell Death Dis. 2019;10(1):18. doi: 10.1038/s41419-018-1272-8.

6. Li Q, Li H, Xu T, Du H, Gang CH, Fan G, Zhang Y. Natural medicines used in the traditional tibetan medical system for the treatment of liver diseases. Front Pharmacol. 2018;9:29- 
48. doi: 10.3389/fphar.2018.00029.

7. Xiong F, Guan Y. Cautiously using natural medicine to treat liver problems. World J Gastroenterol. 2017;23(19):338895.

8. Zhang Y, Gan R, Li S, Zhou Y, Li A, Xu D. Antioxidant phytochemicals for the prevention and treatment of chronic diseases. Molecules. 2015;20:21138-56. doi: 10.3390/ molecules201219753.

9. Wani S, Hussain P, Masoodi FA, Ahmad M, Wani T, Gani A, et al. Evaluation of the composition of bioactive compounds and antioxidant activity in fourteen apricot varieties of North India. J Agric Sci. 2017;9(5):66-82.

10. Sochor J, Zitka O, Skutkova H, Pavlik D, Babula P, Krska $\mathrm{B}$, et al. Content of phenolic compounds and antioxidant capacity in fruits of apricot genotypes. Molecules. 2010;15(9):6285-6305. doi: 10.3390/molecules15096285.

11. Kan T, Gundogdu M, Ercisli S, Muradoglu F, Celik F, Gecer MK, et al. Phenolic compounds and vitamins in wild and cultivated apricot (Prunus armeniaca L.) fruits grown in irrigated and dry farming conditions. Biol Res. 2014;47(1):46.

12. Gupta S, Chhajed M, Arora S, Thakur G, Gupta R. Medicinal value of apricot: A review. Indian J Pharm Sci. 2018;80(5):790-794.

13. Kamel G, Awad NE, Shokry AA. Phytochemical screening, acute toxicity, analgesic and anti-inflammatory effects of apricot seeds ethanolic extracts. J Applied Vet Sci. 2018;3(1):26-33.

14. Michalcová K, Halenár M, Tušimová E, Kováčik A, Chrastinová L, Ondruška L, et al. Blood plasma levels of anterior pituitary hormones of rabbits after apricot seed exposure in vivo. J Cent Eur Agric. 2016;17(4):1241-1252. doi: $\quad$ 10.5513/JCEA01/17.4.1838

15. Salama R, Ramadan A, Alsanory T, Herdan M, Fathallah O, Alsanory A. Experimental and therapeutic trials of amygdalin. Int J Biochem Pharmacol. 2019;1:21-26.

16. Halenar M, Medvedova M, Maruniakova N, Kolesarova A. Amygdalin and its effects on animal cells. J Microbiol Biotechnol Food Sci. 2013;2:1414-23.

17. Shi J, Chen Q, Xu M, Xia Q, Zheng T, Teng J, et al. Recent updates and future perspectives about amygdalin as a potential anticancer agent. Cancer Med J. 2019; 8:30043011.

18. Pareek A, Godavarthi A, Issarani R, Nagori BP. Antioxidant and hepatoprotective activity of Fagonia schweinfurthii (Hadidi) Hadidi extract in carbon tetrachloride induced hepatotoxicity in HepG2 cell line and rats. J Ethanopharmacol. 2013;150(3):973-981. doi: 10.1016/j. jep.2013.09.048.

19. Kumar A, Sunita P, Pattanayak SP. Silibinin inhibits the hepatocellular carcinoma in NDEA-induced rodent carcinogenesis model: an evaluation through biochemical and bio-structural parameters. J Cancer Sci Ther. 2015;7(7):207-216.

20. Sundaresan S, Subramanian P. S-allylcysteine inhibits circulatory lipid peroxidation and promotes antioxidants in N-nitrosodiethylamine-induced carcinogenesis. Pol J Pharmacol Pharm. 2003;55(1):37-42.

21. Shaarawy SM, Tohamy AA, Elgendy SM, Elmageed ZY, Bahnsy A, Mohamed MS, et al. Protective effects of garlic and silymarin on NDEA- induced rat's hepatotoxicity. Int J Biol Sci. 2009;5(6):549-557.

22. Pan SY, Zhou S, Gao SH, Yu ZL, Zhang SF, Tang MK, et al. New Perspectives on how to discover drugs from herbal medicines: CAM's outstanding contribution to modern therapeutics. Evid Based Complement Alternat Med. 2013;2013:627375. doi: 10.1155/2013/627375.

23. Amaya-Salcedo JC, Cárdenas-González OE, GómezCastaño JA. Solid-to-liquid extraction and HPLC/UV determination of amygdalin of seeds of apple (Malus pumila Mill): Comparison between traditional-solvent and microwave methodologies. Acta Agron. 2018;67(3):381388.

24. Bolarinwa IF, Orfila C, Morgan MRA. Amygdalin content of seeds, kernels and food products commercially-available in the UK. Food Chem. 2014;152:133-9. doi: 10.1016/j. foodchem.2013.11.002.

25. Yurt B, Celik I. Hepatoprotective effect and antioxidant role of sun, sulphited-dried apricot (Prunus armeniaca L.) and its kernel against ethanol-induced oxidative stress in rats. Food Chem Toxicol. 2011;49:508-13.

26. Abdel-Rahman MK. Can apricot kernels fatty acids delay the atrophied hepatocytes from progression to fibrosis in dimethylnitrosamine (DMN)-induced liver injury in rats? Lipids Health Dis. 2011;10:114-124. doi: 10.1186/1476511X-10-114.

27. Ordoudi SA, Bakirtzi C, Tsimidou MZ. The potential of tree fruit stone and seedwastes in greece as sources of bioactive ingredients. Recycling. 2018;3:9-28.

28. Zhou Y, Li Y, Zhou T, Zheng J, Li S, Li H. Dietary natural products for prevention and treatment of liver cancer. Nutrients. 2016;8:156-179. doi: 10.3390/nu8030156.

29. Sivaramakrishnan V, Shilpa PNM, Kumar VP, Devaraj $\mathrm{SN}$. Attenuation of N-nitrosodiethylamine - induced hepatocellular carcinogenesis by a novel flavonol-Morin. Chem Biol. 2008;171:79-88.

30. Gulati K, Reshi MR, Rai N, Ray A. Hepatotoxicity: Its mechanisms, experimental evaluation and protective strategies. Am J Pharmacol. 2018;1(1):1004-1013.

31. Mukherjee D, Ahmad R. Dose-dependent effect of N'Nitrosodiethylamine on hepatic architecture, RBC rheology and polypeptide repertoire in Wistar rats. Interdiscip Toxicol. 2015;8(1):1-7. doi: 10.1515/intox-2015-0001.

32. Usunomena U, Joel JS, Nwangwu S, Esosa US, Kingsley O, Maduagwu E. Toxicity evaluation of the liver and in vitro metabolism in Wistar rat on exposure to $\mathrm{N}$-nitrosamine percursors. Br J Pharmacol Toxicol. 2011;2:138-142.

33. Keshari AK, Singh AK, Kumar U, Raj V, Rai A, Kumar P, et al. 5H-benzo[h]thiazolo[2,3-b]quinazolines ameliorate NDEA-induced hepatocellular carcinogenesis in rats through IL-6 downregulation along with oxidative and metabolic stress reduction. Drug Des Devel Ther. 2017;11:2981-2995. doi: 10.2147/DDDT.S143075

34. Ali SA, Ibrahim NA, Mohammed MMD, El-Hawary S, Refaat EA. The potential chemo preventive effect of ursolic acid isolated from Paulownia tomentosa, against N-diethylnitrosamine: initiated and promoted hepatocarcinogenesis. Heliyon. 2019;5(5):e01769. doi: 10.1016/j.heliyon.2019.e01769.

35. AlSalloom AAM. An update of biochemical markers of 
hepatocellular carcinoma. Int J Health Sc. 2016;10(1):122136.

36. Perumal S, Langeshwaran K, Selvaraj J, Ponnulakshmi R, Shyamaladevi B, Balasubramanian MP. Effect of diosmin on apoptotic signaling molecules in Nnitrosodiethylamineinduced hepatocellular carcinoma in experimental rats. Mol Cell Biochem. 2018;449:27-37.

37. Bilal N, Suhail N, Hasan S, Ashraf GM, Fatima S, Khan $\mathrm{HY}$, et al. Exacerbation of N-nitrosodiethylamine induced hepatotoxicity and DNA damage in mice exposed to chronic unpredictable stress. Front Pharmacol. 2017;8:360370. doi: 10.3389/fphar.2017.00360.

38. Gaschlera MM, Stockwellb BR. Lipid peroxidation in cell death. Biochem Biophys Res Commun. 2017;482(3): 419425.

39. Idelman G, Smith DLH, Zucker SD. Bilirubin inhibits the up-regulation of inducible nitric oxide synthase by scavenging reactive oxygen species generated by the toll like receptor 4-dependent activation of NADPH oxidase. Redox Biol. 2015;5:398-408.

40. Kurutas EB. The importance of antioxidants which play the role in cellular response against oxidative/nitrosative stress: current state. Nutr J. 2016 Jul 25;15(1):71. doi: 10.1186/ s12937-016-0186-5.

41. Kidd P. Glutathione: Systemic protectant against oxidative and free radical damage. Alt Med Rev. 2016;2(3):155-177.

42. Kujawska M, Ewertowska M, Adamska T, Ignatowicz E, Gramza-Michałowska A, Jodynis-Liebert J. Protective effect of yellow tea extract on N-nitrosodiethylamineinduced liver carcinogenesis. Pharm Biol. 2016;54(9):1891900. doi: 10.3109/13880209.2015.1137600.

43. Srivasstava N. Vitamin B17 and its proposed application in treating cancer. Interdisciplinary J Contemp Res. 2016;3(6):109-112. 